\title{
NUMERALS VERSUS WORDS FOR EFFICIENCY IN READING
}

\author{
MILES A. TINKER \\ University of Minnesota
}

The purpose of this study was to investigate whether numbers in the form of printed words or as Arabic numerals, when used in the context of arithmetical problems, bring greater reading efficiency as measured by speed of reading. The attempt was made to maintain comprehension approximately constant. In scientific material the practice of printing numbers varies with authors. Often a single writer is not consistent. Words are sometimes employed and at other times Arabic numerals are used. There is a tendency perhaps to print unit numbers as words more often, and to print numbers of two or more digits as numerals. Numbers which occur as the first item of a sentence are almost invariably in the form of words. In arithmetical or algebraic problems as well as in those of exact sciences numbers usually appear as numerals. Formulae and equations always employ numerals.

Numerals are symbolizations which represent a large amount of abbreviation in comparison with words. This abbreviation exhibits itself in part by requiring much less space on the printed page, for such printing is more compact.

Landolt (6) found that in reading a series of figures, very short and rapid eye movements were involved. There appeared to be about one move for each digit read. Employing a photographic technique Dearborn (1) discovered in reading numbers that the attention was concerned with much smaller units than in reading words of ordinary prose selections. The

1 The data for this experiment were collected at Stanford University in the spring of 1927 . 
large number of fixations used demonstrated a more analytical type of reading for the numbers. As many as 30 shifts of the eye appeared in the reading of a series of 24 digits, but when the digits were in groups of 3 or 4 the number of fixations per digit was comparatively fewer. Terry (10) with a similar method, found that numerals in arithmetical problems required more fixations per unit space covered than did the accompanying words and that the fixations on numbers had a longer pause duration than those on words of the context. Larger groups of digits made greater demands on the eye and on attention than the smaller groups. From 1 to 3 digits were read per pause; the number varying with the observer. A single fixation usually sufficed for reading numbers of 1 or 2 digits. In a photographic study Tinker (11) found that the reading of algebraic formulae in context required many more fixations per unit space covered than the reading of either scientific prose or algebraic narrative. For lines composed entirely of formulae he found that the reading was essentially analytical in nature. Such reading was characterized by a comparatively large number of fixations per line and these increased in number with the complexity of the formulae. Pause duration in reading formulae was longer than in reading prose. In this same study it was found that in general, more formulae items were read per fixation than words of prose. However, because the fixational pauses were longer in duration for reading formulae than for prose, more words of prose were read per second than items of formulae. It must be noted that in reading formulae or equations the reader has to grasp relationships between the various parts involved as well as apprehend the separate items of such formulae or equations. The comprehension of these relationships necessarily must be a factor which tends to reduce speed of reading. Judd and Buswell (5) have shown that the nature of eye movements appears to be closely related to the nature of the mental processes involved in the reading.

To sum up, these studies indicate that numbers and formulae are read with more and longer fixations per unit space than the accompanying context or ordinary prose. However, in reading 
numbers or formulae, the eye has much less spacial extent to cover than in reading the same material printed in words. The question arises whether numbers in context are read more quickly in the form of numerals or in the form of words when other conditions are kept approximately constant. Is the reading time shortened when the printed symbols are greatly abbreviated in this manner? It is admitted that numerals are more economical from the viewpoint of the printer for they occupy less space on the printed page. Our problem is to investigate their influence on the speed of reading arithmetical problems.

A modified form of the Dodge apparatus for photographing eye movements was used in the first part of this experiment. This apparatus is fully described by Tinker (11) and by Miles and Shen (7). The main features of the apparatus are: A pencil of light from a point source (carbon arc) was reflected into the subject's eye by means of a system of first surface mirrors. This beam of light was interrupted at regular intervals ( $\frac{1}{50}$ second) by a perforated revolving disk. The corneal reflection of this light passed through a lens into a long enlarging camera. At the back of the camera it came to a focus on a continuously moving kinetoscopic film. The direction of the beam of light reflected from the cornea changed with each movement of the reader's eye. Therefore, as the subject read, each fixation was recorded on the film as a sharply focused line. The lines representing fixations were a series of dots rather than solid lines since the beam of light was interrupted at regular intervals. Each dot represented $\frac{1}{50}$ second. Inspection of the film showed the number of fixations employed in the reading and the duration of each fixation.

In the second part of the study the direct method of mirror observation was employed to count the eye movements. A mirror was placed at the right side of the reading-copy so that the experimenter could observe the subject's eye movements during the reading. Counting the eye movements yielded the number of pauses, for a pause follows each movement. 
The material read consisted of the statement and a solution of four arithmetical problems. ${ }^{2}$ Problem A was paired with problem $D$, and $B$ with $C$. One member of each pair contained numbers in the form of numerals and the other contained numbers in the form of words. The alternate problem of each pair was worded slightly different in order to give a new problem but at the same time keep them very similar. The number of letters employed in the two members of a pair were approximately equal (within one letter) with the exception of the numbers. Each problem was typewritten on a separate sheet of paper. The length of the line was about $107 \mathrm{~mm}$. The problems follow in the order A, B, C, D:

\section{A}

If a man can walk five miles an hour, how far does he walk in fifteen hours? The answer is seventy-four miles for five times fifteen is equal to seventy-four.

\section{B}

5 times a certain number decreased by 17 is equal to 18 . What is the number? The number is 7 because 5 times 7 equals 35 and 35 minus 17 is equal to 18.

C

Four times a certain number decreased by thrteen is equal to nineteen. What is the number? The number is eight because four times eight equals thirty-two and thirty-two minus thirteen is equal to nuneteen

D

If a boy can run 6 miles per hour, how far does he run in 14 hours? The answer is 84 miles as 6 taken 14 times makes 84 .

In the first part of the investigation, where the photographic technique was employed four psychology students were subjects. They all had emmetropic vision. All had read material for photographing eye movements before. Prior to taking the records the subjects were required to read 5 pairs of problems similar to the ones used for recording. This pre-

Not necessarily the correct solution. 
liminary work served to acquaint the subjects with the nature of the task and with the type of material to be read. Two subjects read the problems before the camera in the order A, B, C, D; the other two read them in the order D, C, B, A. Comprehension questions were asked after the reading of each problem in the prelimmary exercise as well as in the experiment proper. The subject stated also whether the solution as given was correct.

The procedure for the second part of the experiment was exactly the same with the exception that the mirror method of direct observation was employed. The number of eye movements and the time in seconds required for reading each problem was obtained. A stop-watch was used for timing. Forty college students observed in this part of the experiment. Twenty read the problems in the order A, B, C, D; twenty in the order $\mathrm{D}, \mathrm{C}, \mathrm{B}, \mathrm{A}$.

\section{RESULTS}

The individual as well as the group results obtained by use of the photographic method are given in table 1. In discussing the results we must remember that in selections $A$ and $C$ the numbers are in the form of words and in selections $B$ and $D$ in the form of numerals. $A$ is compared with $D$, and $C$ with $B$. The first column of figures shows that every subject made more fixations when reading the problems which had the numbers in the form of words. On the average there were 6.2 more fixations employed in reading problem A (words) than problem D; 5.3 more fixations for C (words) than B. The next column shows that the number of regressions per problem varies from individual to individual but on the average about the same number was required to read problems with words as problems with numerals. The average duration of fixational pauses shows some individual variation. Most subjects however, have slightly longer pauses in problems employing numerals. This agrees with the findings of Terry (10) and Tinker (11) where pauses on numerals and formulae were longer than these on words. On the average, the pauses in 
TABLE 1

Comparison of the effect of numerals versus words on performance in the reading of arithmetic problems. Photographic method

Tumes in $\frac{1}{50}$ second

\begin{tabular}{|c|c|c|c|c|c|c|}
\hline \multicolumn{2}{|r|}{ SUDJECT* } & $\begin{array}{l}\text { SELEC- } \\
\text { TION }\end{array}$ & $\begin{array}{c}\text { NUMB ER } \\
\text { OF } \\
\text { IIXA- } \\
\text { TIONS } \\
\text { PRR } \\
\text { PROBLEM }\end{array}$ & \begin{tabular}{|c|} 
NUMBMR \\
OF \\
REGRES- \\
S1ONS \\
PEE \\
PROBLEM
\end{tabular} & \begin{tabular}{|c|} 
AVERAGE \\
DUKA- \\
TION OF \\
FIXA- \\
TIONAL \\
PAUERG
\end{tabular} & $\begin{array}{c}\text { PERCRP- } \\
\text { TION } \\
\text { TIME } \\
\text { PER } \\
\text { PROBLEM }\end{array}$ \\
\hline $\mathrm{De}$ & $\cdots, \ldots \cdot \cdots \cdot \cdots$ & $\begin{array}{l}\mathrm{A} \\
\mathrm{D} \\
\mathrm{C} \\
\mathrm{B}\end{array}$ & $\begin{array}{l}22 \\
17 \\
30 \\
19\end{array}$ & $\begin{array}{l}2 \\
1 \\
3 \\
0\end{array}$ & $\begin{array}{ll}12 & 7 \\
14 & 8 \\
14 & 2 \\
16 & 1\end{array}$ & $\begin{array}{l}280 \\
252 \\
425 \\
306\end{array}$ \\
\hline Dr & \multirow[b]{2}{*}{$\cdots \cdots \cdots \cdots \cdot \cdot$} & $\begin{array}{l}A \\
D \\
C \\
B\end{array}$ & $\begin{array}{l}26 \\
21 \\
35 \\
31\end{array}$ & $\begin{array}{l}4 \\
6 \\
6 \\
7\end{array}$ & $\begin{array}{ll}11 & 1 \\
12 & 1 \\
10 & 0 \\
11 & 6\end{array}$ & $\begin{array}{l}290 \\
254 \\
351 \\
361\end{array}$ \\
\hline Ma & & $\begin{array}{l}A \\
D \\
C \\
B\end{array}$ & $\begin{array}{l}26 \\
21 \\
40 \\
38\end{array}$ & $\begin{array}{r}3 \\
2 \\
10 \\
11\end{array}$ & $\begin{array}{ll}13 & 5 \\
15 & 0 \\
13 & 9 \\
13 & 6\end{array}$ & $\begin{array}{l}353 \\
315 \\
558 \\
518\end{array}$ \\
\hline $\mathrm{Ri}$ & $\cdots \cdots \cdots \cdots$ & $\begin{array}{l}\mathrm{A} \\
\mathrm{D} \\
\mathrm{C} \\
\mathrm{B}\end{array}$ & $\begin{array}{l}39 \\
29 \\
42 \\
38\end{array}$ & $\begin{array}{l}7 \\
8 \\
6 \\
7\end{array}$ & $\begin{array}{ll}12 & 5 \\
12 & 4 \\
12 & 6 \\
13 & 9\end{array}$ & $\begin{array}{l}490 \\
360 \\
533 \\
530\end{array}$ \\
\hline \multicolumn{2}{|c|}{ Average of 4 subjects } & $\begin{array}{l}A \\
D \\
C \\
B\end{array}$ & $\begin{array}{ll}28 & 2 \\
22 & 0 \\
36 & 8 \\
31 & 5\end{array}$ & $\begin{array}{ll}4 & 0 \\
4 & 2 \\
6 & 2 \\
6 & 2\end{array}$ & $\begin{array}{ll}12 & 3 \\
13 & 3 \\
10 & 2 \\
13 & 8\end{array}$ & $\begin{array}{ll}353 & 2 \\
295 & 2 \\
466 & 7 \\
4287\end{array}$ \\
\hline \multicolumn{2}{|c|}{ Words minus Numbers } & $\begin{array}{l}A-D \\
C-B\end{array}$ & $\begin{array}{ll}6 & 2 \\
5 & 3\end{array}$ & $\begin{array}{rr}-0 & 2 \\
0 & 0\end{array}$ & $\begin{array}{ll}-1 & 0 \\
-3 & 6\end{array}$ & $\begin{array}{l}580 \\
380\end{array}$ \\
\hline
\end{tabular}

* Reading records obtained in another investigation (11, table I) show that all these subjects read at about the same rate which was somewhat faster than that of the average reader.

problem $\mathrm{D}$ (numerals) are $1.0 / 50$ second longer than in $\mathrm{A}$; $3.6 / 50$ second longer in $\mathrm{C}$ (numerals) than in $\mathrm{B}$. In the last column is found the perception time for each problem. The 
perception time is the sum of the pause durations. ${ }^{3}$ All but two observers show a shorter perception time for problems with numerals than for those with words. Subject $R$ i showed this same advantage in reading $A$ and $D$ but the perception time for $\mathrm{C}$ and $\mathrm{B}$ are approximately equal Also subject $\mathrm{Dr}$ had a slightly longer perception time for $B$ than $C$. On the average $D$ was read $58 / 50$ second faster than $A ; B, 38 / 50$ second faster than $\mathrm{C}$.

TABLE 2

Comparison of the effect of numerals versus words on performance in reading arithmetic problems. Direct method

Times in seconds*

\begin{tabular}{|c|c|c|c|}
\hline & BELECTION & $\begin{array}{c}\text { NUMBER } \\
\text { OF } \\
\text { FIXATIONS } \\
\text { PER } \\
\text { PROBLIX } \\
\end{array}$ & $\begin{array}{l}\text { READING } \\
\text { TIME PER } \\
\text { PBOREEM }\end{array}$ \\
\hline A verage of 40 subjects & $\begin{array}{l}\mathrm{A} \\
\mathrm{D} \\
\mathrm{C} \\
\mathrm{B}\end{array}$ & $\begin{array}{l}146 \\
12.4 \\
217 \\
157\end{array}$ & $\begin{array}{rl}116 & 6 \\
9 & 8 \\
15 & 7 \\
11 & 3\end{array}$ \\
\hline Words minus Numbers & $\mid \begin{array}{l}A-D \\
C-B\end{array}$ & $\begin{array}{ll}2 & 2 \\
6 & 0\end{array}$ & $\begin{array}{l}1.8 \\
44\end{array}$ \\
\hline
\end{tabular}

* The writer wishes to express his thanks to T. J. Keegan for collecting the data represented in this table.

A summary of the results obtained by the mirror method of direct observation is given in table 2. The method of direct observation is, of course, much less accurate than photographic methods. However, as the results obtained by the direct method as here used show exactly the same trends as those found by the photographic method, the writer considers them worth citing. In the first column of figures in table 2 , the average of 40 subjects shows that problem A (numerals) was

3 Erdmann and Dodge (4) found that $\frac{1}{13}$ to $\frac{28}{24}$ of the time consumed in reading a line of print is taken up by the fixational pauses. According to Shen $(9)$ these figures should be $\frac{1}{2} \frac{9}{8}$ to $\frac{29}{8} \frac{1}{y}$. Dodge $(2,3)$ has shown that there is no clear vision during saccadic eye movements (used in reading). 
read with 2.2 more fixations than $\mathrm{D}$; problem $\mathrm{C}$ with 6.0 more fixations than B. The reading time, given in the last column, was 1.8 seconds less for $D$ (numerals) than $A ; 4.4$ seconds less for $B$ (numerals) than $C$.

Comparison of the results given in tables 1 and 2 shows that they are in close agreement. Problems with the numbers as numerals are read with fewer fixations and at a faster rate than where the numbers are in the form of words. This means that the large amount of abbreviation achieved in symbols by printing numbers in the form of numerals rather than words favors faster reading. This is shown by the fewer fixations employed and a shorter total reading time for the context involving numerals. This seems to indicate that spacial extent, when the content remains approximately constant, is a factor in determining speed of reading in such material as arithmetical problems. Thus some numbers, as 35 (thirtyfive) or 84 (eighty-four), cover considerable space when printed as words but only a very small extent when in the form of numerals. Terry's investigation (10) shows that such numerals as $2,47,357$, and 617,453 were at times read with one, one, one, and three fixations respectively. This indicates that for numerals of these lengths, more digits were read per pause for the longer numerals. If the numbers just cited were expressed in words, there would be at least one word for each digit used (counting a hyphenated word as 2 words). From table XVII of Terry's report (10) it was calculated that on the average, 1.49 words of the context were read per pause, and 2.39 digits per pause. Calculations from material in tables XVII and XVIII show that Terry's subjects read 6.80 words of the context per second and 7.93 digits per second. If these numbers were in word-form and read at the same rate as words of the context, it would retard reading more than if numerals were used. The above indicates that the reading of the various symbols in numerals is faster than the reading of words in the context. Let us extend this comparison to numbers as numerals versus numbers printed as words. If compared in this way Terry's results correspond to our findings. As cited above, Tinker found that more words of prose were read per 
second than items of formulae. Here the reading situation was different than in reading numbers in problems. Comprehension of relationships between various parts of the formulae as well as apprehension of formulae items was necessary.

In two previous studies the writer showed that there appears to be some configuration present in the reading of numerals consisting of two to three digits (12), and in reading formulae (13) where there was a tendency toward grouping into higher perceptual units. It is probable that such configuration would be much decreased or entirely absent where the material is expressed altogether in words. This would be especially true with formulae where the compact arrangement facilitates the grasping of relationships between the various parts of the formula.

The data given in tables 1 and 2 allow us to estimate the reliability of the direct method of observing eye movements. For the determination of the absolute number of eye movements in reading the method is evidently unreliable. The average number of fixations per selection, as given in table 2 , is considerably smaller for each selection than those given in table 1, even though the subjects in table 1 were all fast readers. However, for comparing the differences in the number of fixations made in reading different selections, the mirror method of direct observation possesses a fair reliability, providing a rather large number of subjects are used in the experiment. The fact that the comparisons given in table 2 show the same trend as those in table 1 support this contention. Pressey (8) has found the direct method of observing eye movements useful in an investigation of reading proficiency.

\section{SUMMARY AND CONCLUSIONS}

1. A comparison was made between the speed of reading arithmetical problems with numbers printed in the form of words and as numerals to determine the effect of the greater compactness achieved in the latter.

2. The photographic method of recording eye movements was used for obtaining reading records from 4 subjects, and the mirror method of direct observation with 40 subjects. 
3. The photographic records showed that for problems where the numbers were in the form of words the reading involved more and slightly shorter fixations and a longer perception time. With the method of direct observation it was found that more fixations and a longer reading time were present where numbers appeared as words. Thus the results from the two groups were in close agreement.

4. These results warrant the conclusion that the compactness of printing achieved by employing numerals rather than words brings about faster reading when other conditions remain approximately constant.

\section{REFERENCES}

(1) Dearbonn, W. F. The Psychology of Reading New York, 1906; also as Columbia Unıv. Contr to Phil and Psych, xiv, no. 1, 1906

(2) Dodge, Raymond. The illusion of clear vision during eye movement. Psych. Bull , 1905, 2, 193-199

(3) Dodag, Rarmond Visual perception during eye movement. Psych Rev., 1900, 7, 454-465

(4) Erdmann, B., and Dodge, R.: Psychologische Utersuchungen uber das Lesen auf experimenteller Grundlage, Halle, 1898.

(5) Judd, C H., AND Buswell, G. T.. Silent readung, a study of the various types Suppl Educ. Monog., no. 23, 1922

(6) Landout: Nouvelles Recherches sur la physiologie des mouvements des yeux Archives D'Ophtalmologie, 1891, 11, 385-395.

(7) Mrles, W R., AND Shen, E . Photographic recording of eye movements in the reading of Chinese in vertical and horizontal axes: method and preliminary results. Jour Exper. Psych., $1925,8,344-362$.

(8) Pressex, L C - Specific elements making for proficiency in silent reading when general intelligence is constant School and Soc., $1926,24,589-592$

(9) Shen, $\mathrm{E} \cdot$ An analysis of eye movements in the reading of Chinese. Jour. Exper Psych, 1927, 10, 158-183.

(10) Terry, P. W. How numerals are read. Suppl Ed Monog., no. $18,1922$.

(11) Tinker, M A.. A photographic study of eye movements in reading formulae. Genetic Psychology Monographs (in press).

(12) Trnker, Mrtes A . Reading reactions for mathematical formulae. Jour. Exper Psych., 1926, 9, 444-467.

(13) Triker, M A.: How formulae are read Amer Jour. Psych. (in press). 